\title{
Computation and Clay: Evolving Fabrication and Performance Strategies for Ceramics in Architecture
}

FRANK MELENDEZ

The City College of New York
Throughout civilization, fired clay has taken on various roles, ranging from utilitarian objects to decorative art. In architecture, fired clay, as a building material, demonstrates a wide range of uses. Typically used as a tiling system, ceramics have provided a means of waterproofing buildings, protecting structures from fires, and as an aesthetic device for decorating surfaces. This is true of historical and contemporary buildings, in both Eastern and Western cultures. Ceramics have a long standing role as a ubiquitous building material and its production has evolved throughout the history of architecture, from manual, to industrial, and now digital processes.

The use of ceramic tiles in the built environment is vast, ranging from mass produced and assembled processes, to highly skilled and customized modes of craft. This paper presents a series of research projects, collectively titled Computation and Clay, that examine new possibilities for ceramics in architecture through the use of slip-casting, computation, and digital tooling, merging traditional and contemporary methods of making.

\section{COMPUTATIONAL DESIGN AND PATTERNING}

The Computation and Clay projects developed from a series of advanced, research-based architectural design courses, titled Digital Craft, which were developed and taught at Carnegie Mellon University and Louisiana State University. These seminar courses focused on the subjects of ornament and craft through the exploration of computationally generated patterns, digital fabrication processes, and casting techniques for phase-change materials (liquid to solid). 'Acuity' patterns, as described in Patricia Rodeman's "Psychology and Perceptions of Patterns in Architecture", were studied as a means of producing psychological and/or physiological affects by creating illusions of movement through the use of high contrasting and regimented geometries. ${ }^{1}$ Algorithmic design processes were used to generate patterns and speculate on their effects.

Digital tooling strategies utilizing CNC-milling processes were explored to fabricate the intricate and complex geometries that resulted through the computationally designed patterns. Through the modification of machining variables, such as material selection, cutting speed, and bit sizes, the CNC milling machine was used to explore the crafting of surface effects in contemporary architecture. ${ }^{2}$ Molds were made from the digitally fabricated 'master' parts, 
and used to cast phase change materials, that transformed from liquid to solid, such as resin, concrete, and ceramic slip. Casting out of various materials was encouraged as a method for discovering unanticipated qualities, attributes, and expressions of the material. The molds also provided a means for casting multiple identical components that could be assembled to form larger surfaces and fields.

This process established a heuristic approach to learning by providing students with a basic workflow for design and fabrication, while allowing them to discover new opportunities for materials and their potentials for effects and performance. In these studies and experiments, the slip-casting technique and ceramic material stood out from the others in that, the cast part contains a hollow cavity, creating a void space that makes it light in weight. The material also undergoes a transformation when firing, in form and scale, and seems to provide more opportunities for surface finishing. These observations lead to more in depth research into the historical use of ceramics in architectural design.

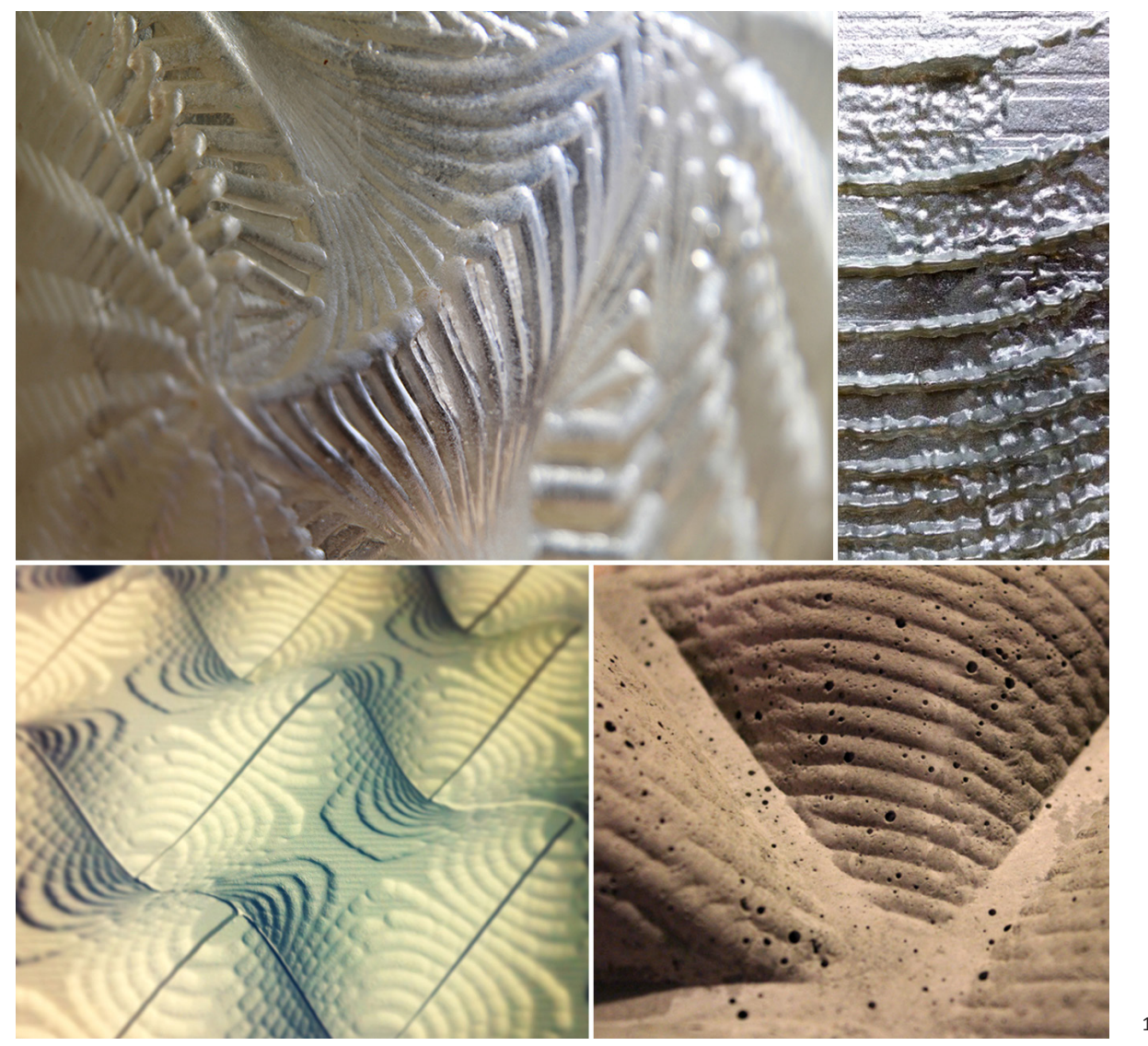

\section{HISTORICAL EXAMPLES OF CERAMICS IN ARCHITECTURAL DESIGN}

The use of ceramics has a long history dating back thousands of years. Etymologically, the term "ceramic" stems from the Greek term "keramos" meaning "the potter's clay", and is derived from an older Sanskrit root, meaning "to burn". ${ }^{3}$ These definitions describe the material, but also highlight the importance of the process. Clay is a plastic, malleable material which, when fired, undergoes a transformation and hardens. These drastic changes within the material provide both high levels of flexibility, in sculpting forms and shapes, as well as durability, against the effects of weathering. The permanent aspect of ceramics has served to date archeological digs and has helped to preserve information which may have otherwise been lost. The earliest examples of ceramics include utilitarian objects in the form of pottery, made from clay, densified during the sintering process. Over time, decorative patterns and motifs were applied to utilitarian objects by imprinting the clay, or coloring the

Figure 1: Digital Craft student work 
clay through glazing techniques, prior to firing. This combination of utility and decoration can be traced back to the earliest known examples of ceramics in architectural design.

In Mesopotamia, adobe bricks made from the river mud along the Tigris and Euphrates were used as the main method of building. In the Sumerian city of Uruk (3600-3200 BC), nail shaped ceramic cones were pushed into the outer surface of the adobe walls. This functioned to protect the walls from environmental and weathering factors such as wind and rain. The cone tiles, painted red, white, and black, were geometrically arranged, and served as a decorative pattern. ${ }^{4}$ In the trabeated systems of Ancient Greek architecture, terra cotta tiles were placed on the wooden rafters of sloped roofs in order to protect the structure from rain. Three types of roof tiles systems were developed, each system comprised of various convex and flat tile arrangements. A special tile, the antefix, was placed on the edges of the roof and served as a decorative element used to mask the roof tile joints. The Ancient Roman hypocaust system, was developed to heat bath houses and other buildings. In this system, the floor level was raised, so that warm air from a furnace below could heat the floor. The 'tibuli' tile was a hollow, rectangular, boxed shaped tile that formed walls. The hollow portion of the tile allowed warm air to pass through the walls, and functioned to ventilate smoke out through the roof while radiating heat back into the interior space. The interior surfaces of the tibuli tiles were decorated with reliefs and patterns to enhance the aesthetic experience of the space.

There are countless examples of the use of ceramics in historical and contemporary architecture found throughout the world, and throughout various time periods. This includes the intricate, colorful, mosaic patterns found in Islamic architecture, the sculptural figures and shapes that form the roofs of Asian temples, and modern infrastructural projects that make up our built environment. These and many other examples of ceramics in architecture demonstrate the use of tiling systems that perform specific functions while simultaneously serving to decorate forms and spaces.

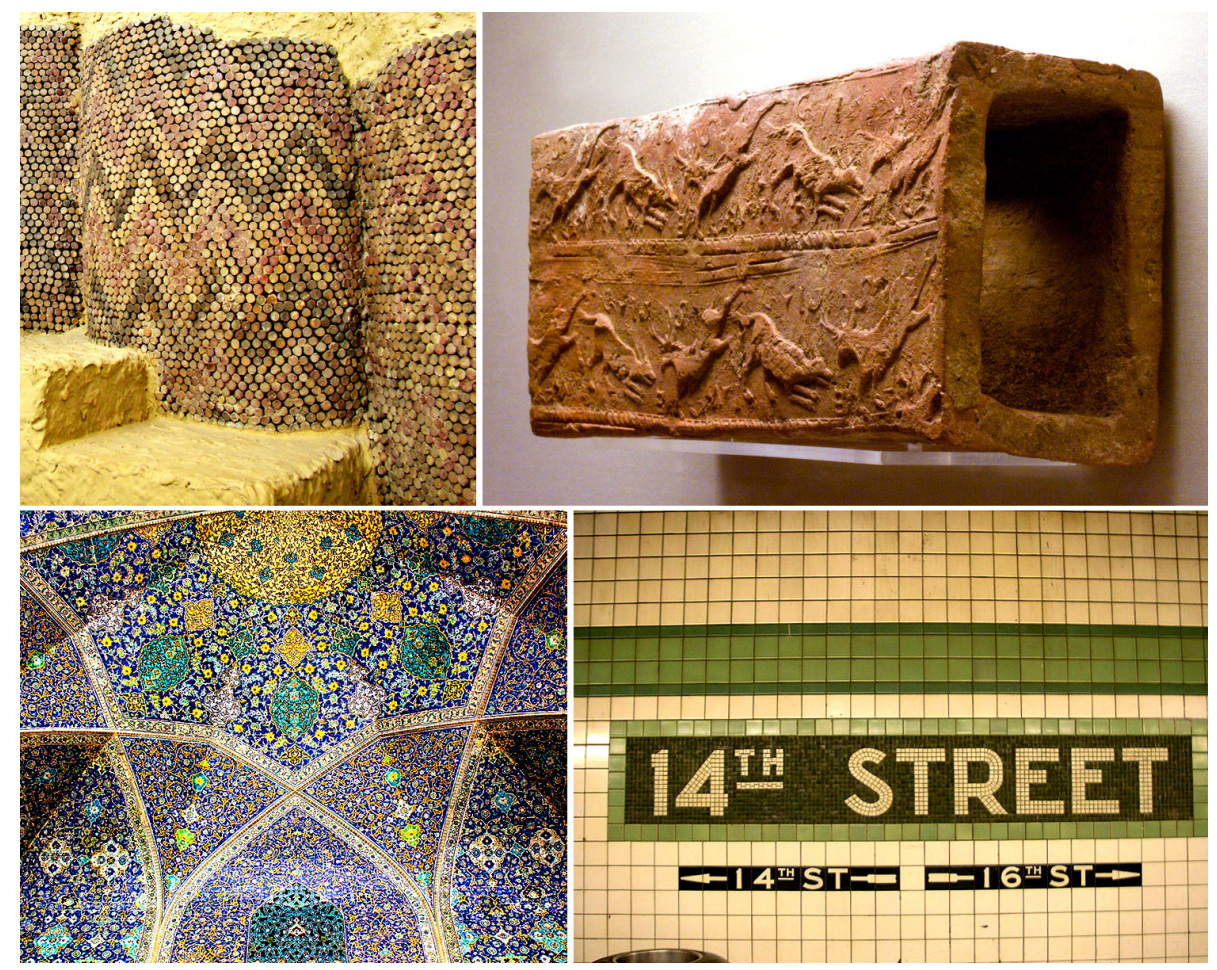

Figure 2: Ceramics in Architecture 


\section{CERAMICS CATEGORIES AND CURRENT MANUFACTURING METHODS}

The three primary categories of ceramics include earthenware, stoneware, and porcelain. These categories are primarily based on the fired density and porosity of the works. During firing sintering takes place, fusing particles at a fast rate and leading to vitrification. Other differences include workability and color. Earthenware is a low fired clay that is non-vitrified, and therefore, not impervious to water unless glazed. Stoneware is vitrified at a particular temperature. Porcelain is vitrified, non-porous and white and glassy in appearance. Additionally, porcelain can exhibit translucent qualities if the surfaces are thin. ${ }^{5}$ Three common methods for forming and shaping clay bodies include hand building, machining, and slip casting. Hand building methods include 'throwing' and 'coiling'. In these techniques, which have been used for centuries, clay bodies are shaped by sculpting the clay by hand. In throwing, the clay is shaped while it is rotating on a wheel, and in coiling, the clay is shaped by stacking rolled, coiled strips of clay. Craftsmanship is the result of the maker's knowledge and workability of the material, where the final form is not completely predetermined, but depends on his or her judgement, dexterity, and care while working. ${ }^{6}$ In hand crafted objects, variation is easy to achieve, and subtle differences occur between copies. Typical industrial manufacturing techniques for ceramics include 'jiggering' and 'extruding'. Jiggering is a mechanized version of wheel throwing, in which the clay body is pressed or stamped by a tool into a mold. Extruding is a mechanized process in which the clay body is pushed through a die of the desired profile or section. Mechanized processes are used to mass produce multiple identical copies. This process removes traditional notions of craft, where the final forms are predetermined and the machines that produce them are calibrated to maximize speed and efficiency. Clay bodies can also be formed by 'slip-casting'. This technique requires a workability by hand but allows for the production of multiple copies. Slip-casting also allows for the production of complex forms and shapes that are difficult to achieve by hand making or industrial processes. In slip casting, a plaster mold is made of the desired form or object. A clay body mixed with water, known as 'slip', is poured into the plaster mold. The plaster mold absorbs water from the clay body through capillary action, drying the clay body that is in contact with the plaster mold. This results in a thickened shell, (the thickness is variable depending on the amount of time that the slip is in the mold), which can be de-molded when the desired thickness is achieved. The process can be repeated to produce multiple parts.

All of these methods yield different possibilities for shaping and forming clay bodies, which remain malleable and plastic until fired. The firing process, typically in a kiln, hardens the clay. The resulting ceramic material can be finished with various types of glazes, which adhere to the ceramic in a second firing, to produce different surface qualities, such as color and reflectance. Glazes also seal and protect the ceramic, and make it impervious to liquids. Within the ceramic manufacturing stages of forming, firing, and glazing, opportunities exist to create variability between copies, where 'identification is based on visual resemblance', and exact replicas between copies, where 'identification is based on visual identicality'. ${ }^{7}$ Digital processes allow fabricated parts to be quickly modified by changing variables within computational models or digital fabrication machinery. Current technologies provide opportunities for architects and designers to fabricate geometrically complex forms and systems through the use of computational design processes and digital fabrication tools that extend the potentials for mass customization. The plasticity of clay bodies make them an ideal material for shaping complex forms and intricate details.

\section{COMPUTATION AND CLAY}

The Computation and Clay research consists of a series of projects that explore the potentials for evolving fabrication and performance strategies for ceramics in architecture through the implementation of computational processes and digital fabrication tools. 
Similar to the merging of utility and decoration in the historical ceramic precedents, these experiments attempt to merge contemporary ornamental qualities of performance and effects. The studies explore computational patterning and a specific digital fabrication technology; 3D printing, CNC milling, and robotic fabrication.

The first project, titled, the Specimen Series, is the result of a collaboration with Justine Holzman of 7B7D. In this project, 3D Printing technologies and computational design tools were used to design a series of ceramic vessels. The forms of the vessels were parametric modeled, allowing for a 'family of forms' to be quickly produced with the modification of a few key variables. An algorithmically designed pattern was applied to the surfaces of the forms in the digital model, producing an intricate, articulated three dimensional surface for the vessel. The pattern produced a textured, field of concave and convex geometries which for gripping the vase, while aesthetically providing a sinuous and undulating surface effect. The digital models were exported and 3D printed out of ABS plastic. A five part plaster mold was produced from the plastic print and served to slip cast multiple components out of porcelain. The slip casting technique allowed the multiple copies of the vessels to remain similar in scale and form. Once fired, various glazing finishes could be applied to each vessel to produce uniqueness, and differences in the finished surface color and reflectance qualities. The project, and the process of making the vessels, yielded unexpected and emergent qualities which were further explored by experimenting with the material and craft.

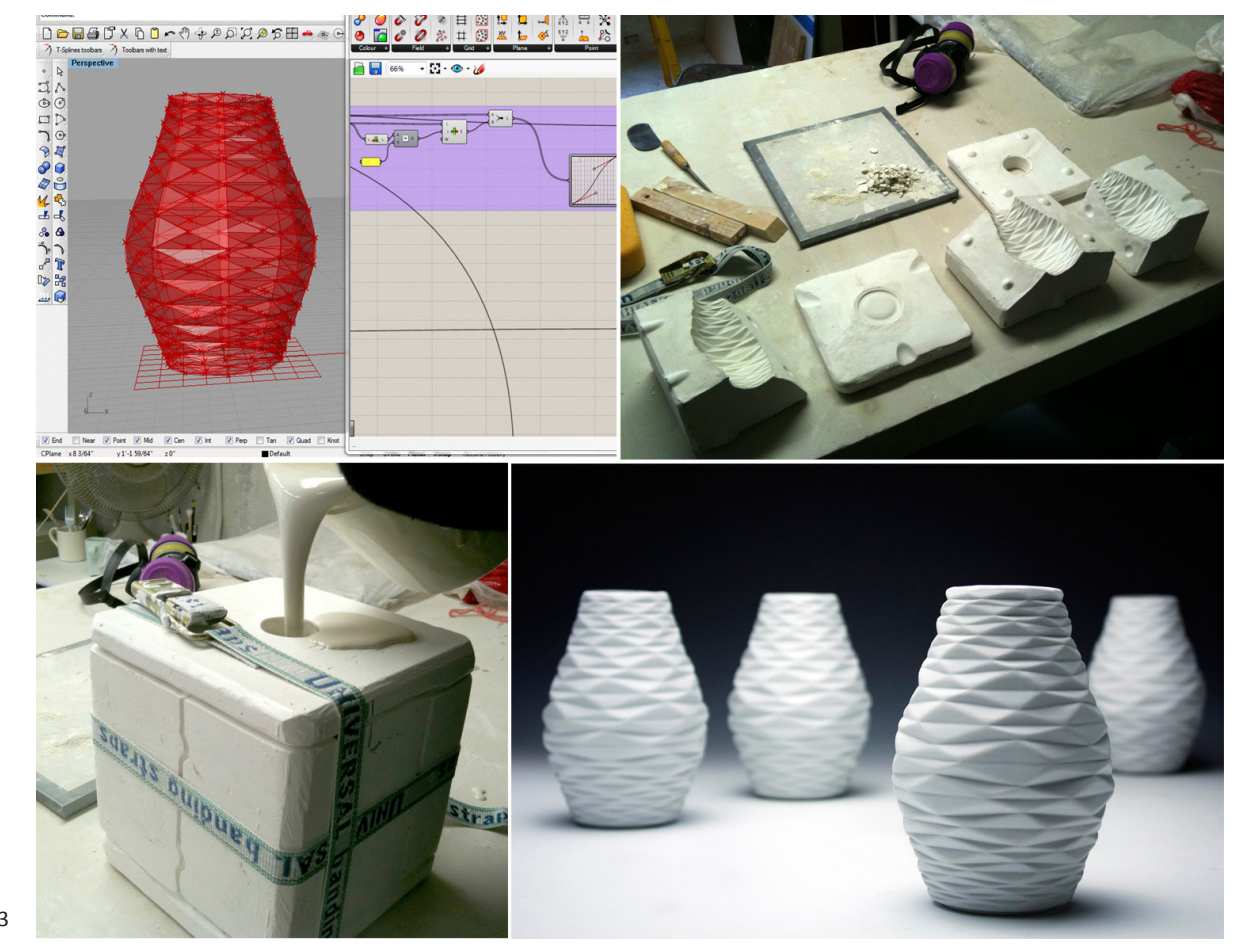

The second project, titled Cairo Bloom, is the result of a collaboration with Seth Payne. The project explores the potential to create a three dimensional tiling system, based on the Cairo Tessellation, that achieves variation within a field through the use of a components with subtle differences. In this study, an algorithmic pattern of curves, within the boundaries of an irregular pentagon, was produced to generate the tooling paths for a CNC milling machine. The variables included the number of divisions, the scale of the aperture in the tile, the displacement of the aperture from the center, rotation of the curves, and the depth of the tile. Rather than digitally modeling a final form, and fabricating an exact replica of the model, this study sought to yield unanticipated and emergent qualities in the surface geometry through the fabrication process. Three components were CNC milled and used to create 
three plaster molds. The two-part molds were used to slip cast over 30 components that can be arranged to form a larger assembly. In this prototype for a wall mounted tiling system, the overall effect of the pattern creates a field of apertures and sinuous curves that imply motion. The aperture in each tile provides an opening into the hollow, void space of the ceramic tile, providing opportunities for various functions. For example, the void space can be used to hold soil and vegetation, to produce a 'green' wall that insulates and increases R-value. In this case, the tooling marks of the surface pattern creates 'channels' which can function to collect rain water and divert water to the plants. In another example, the void space was used to place individual lights. This produced a wall system that provides indirect lighting, achieved by placing LED lights within the cavities of tiles. The lighting pattern was designed to randomly illuminate various tiles, with gradual increases and decreases in brightness controlled through a microcontroller and code. The translucent quality of the porcelain, which is unique to other clay bodies, is exploited to produce a glowing, or blushing, effect.

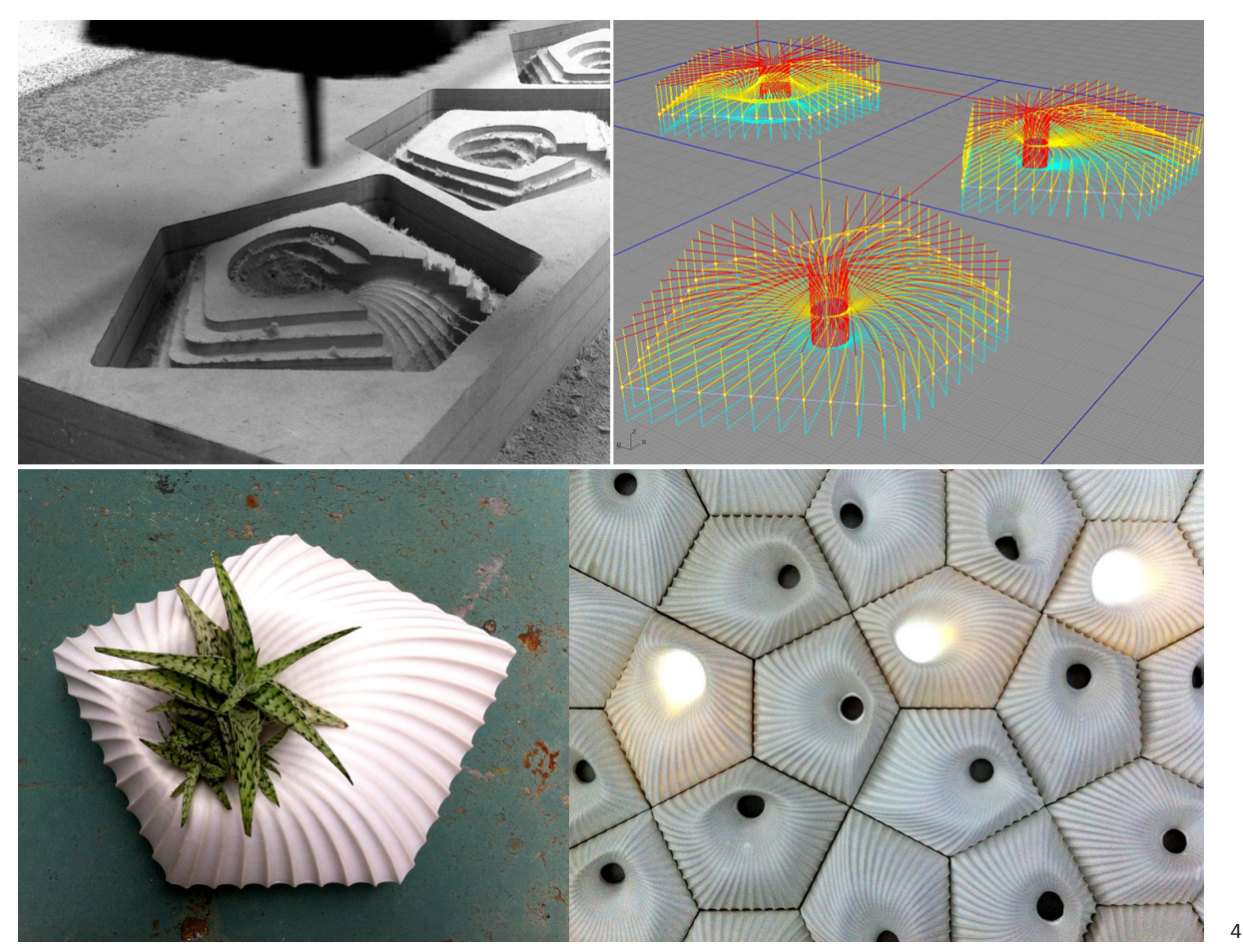

The third project, titled Rob-Plasticity, was made possible with the expertise of Ezra Ardolino, founder of Timbur LLC., digital fabrication specialists servicing Brooklyn, New York City, and the Tri State area. This study, looks into the possibility of manipulating clay through robotic fabrication techniques. A block of earthenware clay was pressed and sculpted through the use of a square shaped wooden peg, attached to the arm of an ABB industrial robot. The project juxtaposes lo-tech and high-tech tools to test the ability to form and shape the plastic nature of the material. Computational patterning techniques were used to create a field of vectors that control the movement and position the robotic arm in space. The project seeks emergent patterns and textures by designing nuances in the motion of the robotic arm. The fabrication software provides opportunities to preview this motion, however, the resulting form and surface articulations yielded emergent qualities, as the behavior of the clay under stresses is difficult to predict or simulate through computation or modeling methods. The resulting pattern varies across the surface and produces a three dimensional texture. In this process, clay can be reshaped to run various tests and iterations, and 
promises reduced amounts of wasted material while maximizing variability. This project is a work-in-progress which opens up exciting possibilities for the integration of robotic fabrication techniques as a means of producing new paradigms in the design of ceramic components and assemblies.

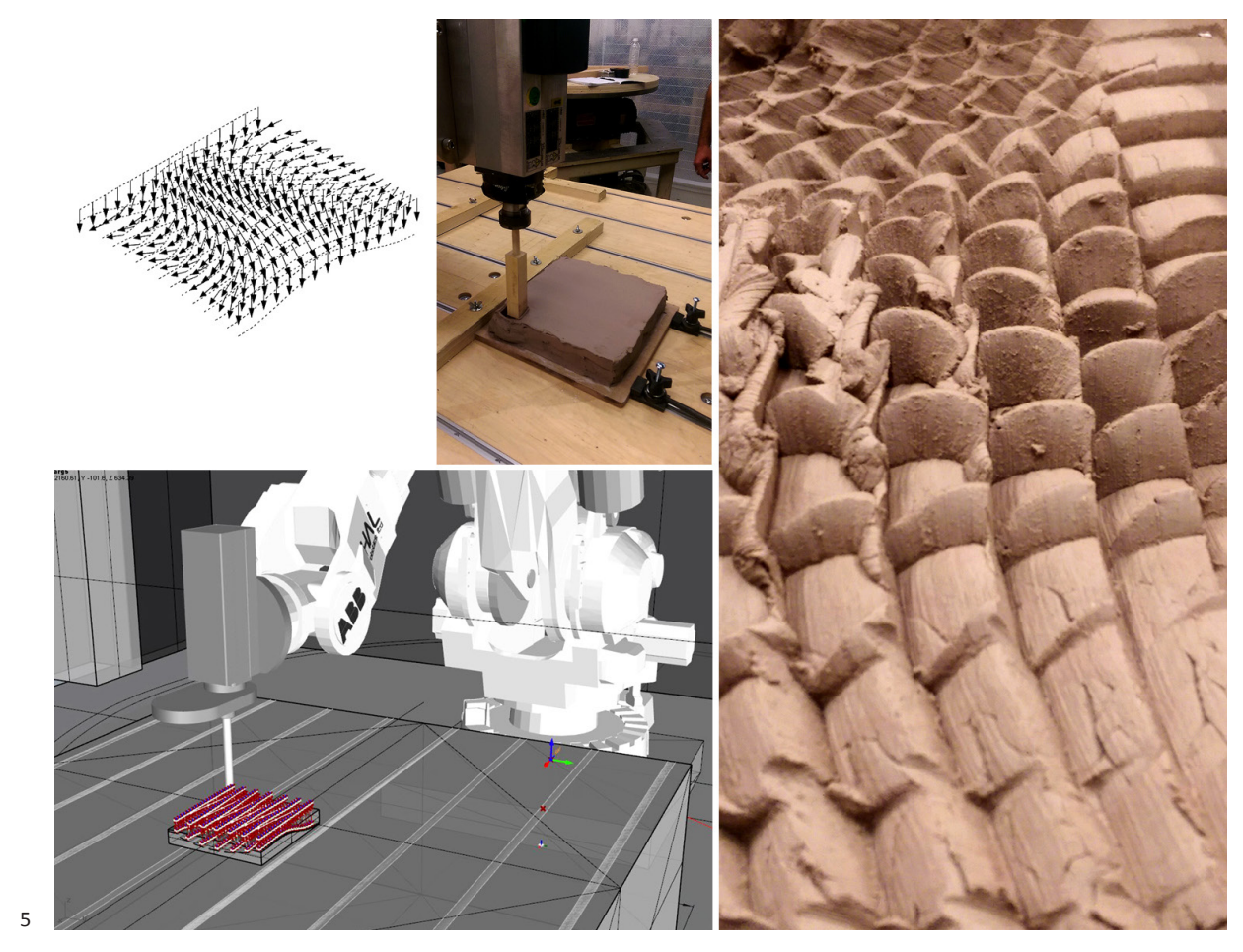

Figure 5: Rob-Plasticity project

\section{ENDNOTES}

1. Rodeman, Patricia. "Psychology and Perception of Patterns in Architecture," AD: Patterns of Architecture, ed. Mark Garcia. (December 2009): 101-107.

2. Kolaravic, Branko and Kevin R. Klinger. Manufacturing Material Effects: Rethinking Design and Making in Architecture, New York, NY: Routledge, 2008.

3. Homer, Staley F., "A Note on the Etymology of the Word "Ceramic", Journal of the American Ceramic Society, Vol.3, No. 7 (July, 1920): 528.

4. Van Lemmen, Hans. $\mathbf{5 0 0 0}$ Years of Tiles, Great Britain: The British Museum Press, 2013.

5. Reijinders, Anton. The Ceramic Process: A Manual and Source of Inspiration for Ceramic Art and Design, London: A\&C Publishers Limited and Philadelphia, PA: University of Pennsylvania Press, 2005.

6. Pye, David. The Nature and Art of Workmanship, Cambridge: Cambridge University Press, 1988.

7. Carpo, Mario. The Alphabet and the Algorithm, Cambridge, Massachusetts: The MIT Press, 2011.

\section{FUTURE POTENTIALS}

The Computation and Clay research seeks to expand on the design and fabrication possibilities of architectural ceramics through the use of digital technologies. Algorithmic design processes provide opportunities to generate forms, shapes, and patterns that are geometrically complex and visually compelling. 3D printing, CNC milling, and robotic fabrication tools offer new possibilities for forming clay bodies into complex forms and geometries. In recent years, computational design strategies coupled with digital fabrication processes have reinvigorated the discourse of ornament in architectural design. Ceramics have contributed to architectural ornament by combining utility and decoration, performance and effect. Their durability, resistance to weathering, and aesthetic qualities, distinguish ceramics as a building material that has maintained a long standing role in architectural design. This role continues to evolve today and has emerged as a design trend that seeks to merge traditional materials and new technologies. 